\title{
MAPEAMENTO DA IMPLANTAÇÃO DO MODELO EMERGENTE DE EDUCAÇÃO
}

\section{MAPPING THE IMPLEMENTATION OF THE EMERGING EDUCATION MODEL}

\section{$\underline{\text { Marcos Antônio Spinassé }}^{1^{*}, \& \text { Blasius Silvano Debald }}{ }^{2}$}

${ }^{1}$ Centro Universitário Salesiano, Centro Universitário Salesiano - UniSales. ${ }^{2}$ Centro Universitário União das Américas de Foz do Iguaçu/PR - UniAmérica.

$1 *$ spinasse@msn.com ${ }^{2}$ blasius.debald@descomplica.com.br

\section{ARTIGO INFO.}

Recebido em: 12.08.2021

Aprovado em: 16.09.2021

Disponibilizado em: 23.09.2021

\section{Palavras-chave:}

Modelo educacional; Instituição de ensino superior; Aprendizagem.

\section{KEYWORDS:}

Educational model; Higher education institution; Learning.

*Autor Correspondente: Spinassé, M. A.

\section{RESUMO}

Em vista a necessidade de adoção de procedimentos adequados a implantação de um novo modelo educacional buscou-se a elaboração de um mapeamento descritivo do processo de inserção que já vem ocorrendo nas instituições de ensino superior. $\mathrm{O}$ processo de inserção modelo educacional emergente se configura por meio de um esquema da Instituição de ensino superior como um organismo composto em três dimensões: (1)Sistema de Aprendizagem; (2)Administração e (3)Infraestrutura. Onde, cada uma das três dimensões (1, 2 e 3 ) seria vista por três prismas: (A)Agentes; (B)Recursos materiais e (C) Processos e apresentas seus elementos.

\begin{abstract}
In view of the need to adopt adequate procedures for the implementation of a new educational model, we sought to draw up a descriptive mapping of the insertion process that has already been taking place in higher education institutions. The emerging educational model insertion process is configured through a scheme of the higher education institution as an organism composed of three dimensions: (1) Learning System; (2) Administration and (3) Infrastructure. Where, each of the three dimensions (1, 2 and 3) would be seen through three prisms: (A)Agents; (B) Material resources and (C) Processes and their elements.
\end{abstract}




\section{Introdução}

O que se apresenta neste trabalho é o resultado da verificação da possibilidade de elaboração do mapeamento do processo de implantação do modelo de ensino-aprendizado do paradigma emergente e, também, da tentativa de torná-lo um esquema estrutural de inserção, a ser utilizada como instrumento de disseminação em outras instituições de ensino superior (IES).

A ideação ontológica aqui exposta se deu por meio da sistematização do procedimento de estabelecimento do atual modelo educacional adotado pelo Centro Universitário Salesiano de Vitória/ES (UniSales) e, também, pelo Centro Universitário União das Américas de Foz do Iguaçu/PR (UniAmérica). Foram propostos as dimensões e os prismas que constituem a estrutura da inserção do modelo educacional adotado no UniSales e, também, no UniAmérica, visando a criação de um sistema de implantação que verteu no esquema do mapeamento do sistema de implantação.

Por volta de 2019 o Centro Universitário Salesiano de Vitória/ES (UniSales) iniciou o processo de implantação de um novo modelo educacional que afetou o paradigma de educação que vinha adotando a quase duas décadas. Este modelo emergente, que impulsiona o estudante a ser protagonista da construção de sua própria competência por meio da aprendizagem baseada em projetos e nas metodologias ativas, tirou o UniSales da zona de conforto e o colocou no caminho da busca do alinhamento de seus processos de ensinoaprendizado à realidade que se apresenta neste século XXI.

O que se passou adotar no UniSales é algo semelhante ao utilizado pelo Centro Universitário União das Américas de Foz do Iguaçu/PR (UniAmérica) desde 2014. O UniAmérica compartilhou seus conhecimentos e experiências colhidos no processo de implementação desse modelo emergente com o UniSales. Foi neste ambiente, de experimentação de algo novo no campo educacional em instituições de ensino superior (IES), que se viu a necessidade de construir uma ontologia gerativa do processo de implantação de um modelo emergente de educação, pois, é provável que haja uma tendência a evolução nos processos de aprendizagem à medida que avança a civilização humana em todos os aspectos.

\section{Percurso metodológico}

Diante do contexto da adoção do paradigma emergente de educação foi possível identificar sinais que evidenciavam a possibilidade da construção de um esquema que representasse a estrutura deste processo. A busca para encontrar os sinais da possibilidade sistematizar o processo de implementação de um modelo educacional, auferiu a este trabalho uma característica de pesquisa exploratória, uma vez que se almejou "proporcionar maior familiaridade com o problema, com vistas a torná-lo mais explícito ou a constituir hipóteses" (Gil, 2002).

Neste contexto, a pesquisa exploratória se deu por meio da pesquisa descritiva, pois, se objetivou ir além "da simples identificação da existência de relações entre variáveis, e pretendem determinar a natureza dessa relação.” (Gil, 2002), uma vez que se pretendeu "proporcionar uma nova visão do problema, o que as aproxima das pesquisas exploratórias."

Por outro lado, também se utilizou a metodologia racional. Rampazzo (2005) afirma que "Os

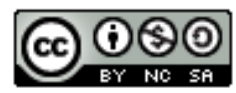


objetos de investigação determinam o tipo de método a ser empregado, a saber: o experimental ou o racional" onde, no método experimental a "investigação nasce de algum problema observado ou sentido" que está materializado e, a partir daí, colhe-se todos os dados possíveis e por indução se chega à conclusão.

A investigação também pode ter como ponto de partida "O questionamento da própria realidade" (Rampazzo, 2005) originado de uma condição apriorística, a qual, por sua vez, pode ser inferida, geralmente, de modo dedutivo e se apresentar conclusões. E, consecutivamente, o método será racional. Desta forma, a partir de algumas reflexões da realidade vivida e experimentada ao longo da implantação do sistema emergente no UniSales, pode-se chegar a alguns sinais da existência do esquema do arcabouço que parecia sustentar o processo de inserção do novo paradigma pelo método racional.

Utilizando como suporte um esquema do mapeamento do processo de implantação educacional ocorrido no UniAmérica e, também, no UniSales, oriundo da reflexão racional, realizou-se entrevistas "estruturada", isto é, "a partir de relação fixa de perguntas" (Gil, 2002) a alguns agentes envolvidos diretamente no processo de implantação do modelo educacional emergente no UniSales a partir do modelo do UniAmérica, a fim, de evidenciar pontos notáveis adequados a ontologia do processo adotado.

Aos entrevistados foi solicitado que discorressem, livremente, sobre a sua percepção do processo de implantação do modelo emergente de educação, considerando a instituição de ensino superior em três dimensões: (1) Sistema de Aprendizagem; (2) Administração e (3) Infraestrutura. Onde, cada uma das três dimensões (1, 2 e 3) seria vista por três prismas: (A) Agentes; (B) Recursos materiais e (C) Processos.

Com o material colhido na entrevista foi feita uma análise de conteúdo que

representa um conjunto de técnicas de análise das comunicações que visam a obter, por procedimentos sistemáticos e objetivos de descrição do conteúdo das mensagens, indicadores (quantitativos ou não) que permitam a inferência de conhecimentos relativos às condições de produção e recepção dessas mensagens (Bardin,1979, p. 42 citado por Gerhardt; Silveira, 2009).

$\mathrm{Na}$ análise de conteúdo adotada buscou-se evidenciar "pouco a pouco uma explicação lógica do fenômeno ou da situação estudados, examinando as unidades de sentido, as inter-relações entre essas unidades e entre as categorias em que elas se encontram reunidas" (Gil, 2002) a fim de se alcançar uma inferência para a esquematização do mapeamento de implantação do modelo educacional do paradigma emergente.

\section{Um esquema hipotético}

Era necessário trazer a existência alguma coisa para que se fosse possível averiguar sua validade como esquema do mapeamento do processo de implantação do modelo emergente de educação em uma instituição de ensino superior. Neste sentido foi realizada uma entrevista, disponibilizada via internet, cuja intenção era encontrar algumas evidências da percepção dos atores que estão na linha de frente da materialização do modelo emergente especialmente em sala de aula, por isto, o formulário foi aplicado, no período de 23/07/2020 a 2707/2020, a 

of Production Engineering, 7(4), Edição Especial "Educação 5.0: Inovação e metodologias ativas para o ensino superior, 1-10.

professores que estão cursando o MBA Gestão de Aprendizagem organizado pelo Uniamérica e realizado pelo UniSales com a participação de 32 respondentes.

A pesquisa era um brainstorm (tempestade de ideias) que pedia para o entrevistado citar palavras e/ou termos que vinham na mente dele quando pensava no novo modelo de educação adotado pelo UniSales. Esta pesquisa demostrou uma tendência mais para o difuso do que para a síntese. A princípio algumas palavras que apreciam de forma mais recorrente eram termos centrais, isto é, eram próprios do modelo emergente, que já permeava o universo perceptivo dos professores como Desafio, Protagonismo, Aprendizagem, Competências, Projetos, mas, também, tinham os termos periféricos como Tecnologia, Inovação, Conhecimento, Mercado. Porém, alguns outros termos pareciam estar ligados ao estado de ânimo do respondente como Mudança, Desafiador, Adequação, Atualização, Potencialmente (existe possibilidade de algo) e outros relacionados ao modelo tradicional como Aluno e Formação.

Diante disto, foi possível inferir que um esquema de implantação não poderia restringir-se somente ao campo educacional, mas, deveria abranger outras dimensões. E o esquema Mapeamento de Implantação (hipotética) (Figura 1), elaborado em um primeiro momento, não dava conta de representar o processo como um todo, pois, era unidimensional, abrangendo somente a dimensão da educação.

Figura 1. Mapeamento de Implantação (hipotética)

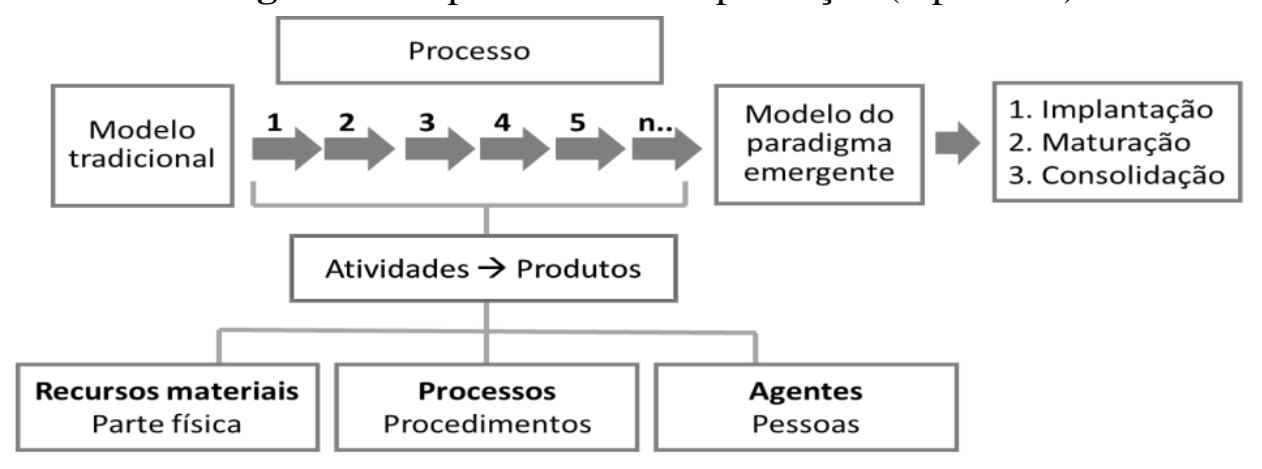

Fonte: Autores (2020)

Encontrou-se mais uma pista em Debald e Golfeto (2016), quando relata que em 2013 houve a Implantação do modelo de aprendizagem baseado em projetos e nas metodologias ativas no UniAmérica e em 2014 houveram Investimentos na formação do quadro docente (dez meses) para difundir a ideia que eles não são eram mais o centro da ação educacional, o modelo educativo, agora, tinha o estudante como protagonista do processo educativo.

Naquele caso teve-se que repensar a docência em um processo concomitante com a implantação do modelo emergente que implicou no perfil estudantil causando um movimento de evasão e consolidação do contingente que só foi se estabilizar em 2016.

No começo, a Instituição perdeu estudantes por transferência, pois não se adaptavam ao modelo, consequência de processos educativos nos quais foram passivos e recebiam tudo pronto. Quando foram desafiados a pensar e romper com a memorização e a reprodução, sentiram-se incapazes e optaram por estudar em outra Instituição. Dois 

of Production Engineering, 7(4), Edição Especial "Educação 5.0: Inovação e metodologias ativas para o ensino superior, 1-10.

anos após a implantação do modelo, a Instituição recebeu mais transferências para ingressantes do que saídas de estudantes. O desempenho dos estudantes melhorou se forem analisados os índices de avaliação (ENADE), assim como o comprometimento aos estudos e o desenvolvimento de competências melhoraram a comunicação, escrita e poder argumentativo (Debald; Golfeto, 2016).

Neste ponto, pode-se perceber que os aspectos de gestão empresarial da instituição são fortemente impactados com a saída e entrada dos estudantes e professores, decorrentes da implantação de um modelo emergente de educação, especialmente no que diz respeito a parte financeira, logo, a inclusão da dimensão administrativa era premente em um esquema de mapeamento de inserção deste novo paradigma.

Diante deste universo, se existe a possibilidade de afetar a dimensão administrativa, o aspecto físico, por implicação, também será influenciado, logo, a dimensão da infraestrutura deveria, também, compor o esquema. Assim o esquema do mapeamento da implantação do modelo emergente educação foi caracterizado por três dimensões, a saber: (1) Sistema de Aprendizagem; (2) Administração e (3) Infraestrutura.

O esquema unidimensional do mapeamento de Implantação (hipotética) (Figura 01), mesmo não conseguindo abarcar a existência na totalidade do processo de implantação, traz elementos operacionais adequados para contemplar a realidade por três prismas, que são: (A) Agentes; (B) Recursos materiais e (C) Processos.

Nesta linha de raciocínio, se chegou ao esquema da instituição de ensino superior como um organismo (Figura 2), onde o ambiente acadêmico, espaço existencial do aprendente, se realiza pela interseção das três dimensões e, cada uma, contempla a realidade operacional por três prismas.

Figura 2. Instituição de ensino superior como um organismo.

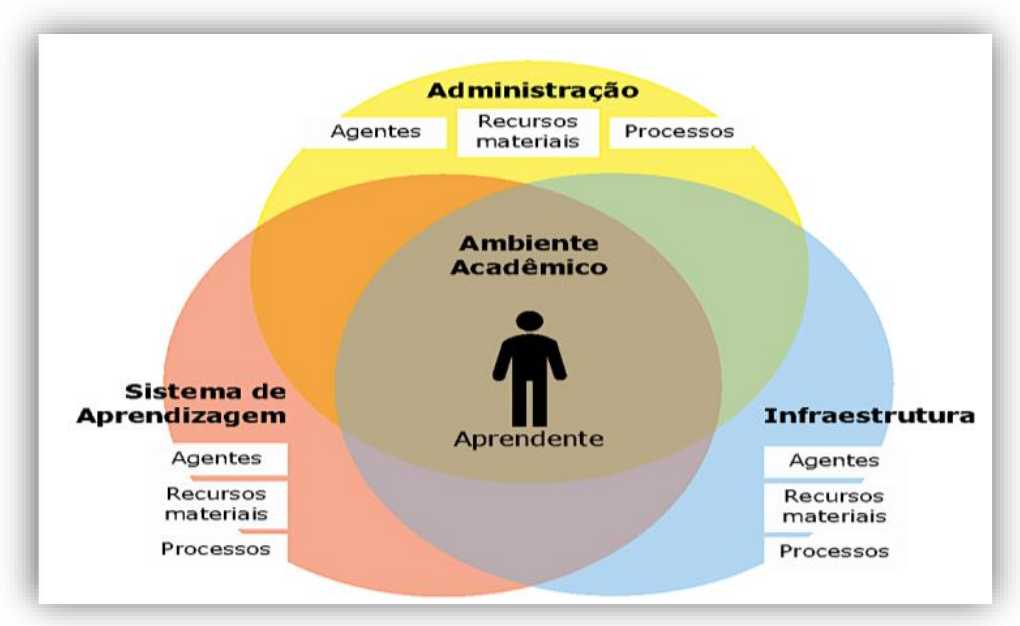

Fonte: Autores (2020)

A analogia da instituição de ensino superior como organismo, tem gênese no processo de adaptação que ocorre pela transição do modelo tradicional para o modelo emergente que influencia radicalmente a configuração de um estado original para outro que surge.

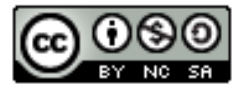



of Production Engineering, 7(4), Edição Especial "Educação 5.0: Inovação e metodologias ativas para o ensino superior, 1-10.

O esquema do sistema de implantação de um modelo emergente de educação em uma IES (Figura 3) se fundamenta na teoria sintética da evolução (Neodarwinismo) que leva em conta que as mutações, recombinações gênicas, e a seleção natural e se caracterizam como as razões predominantes que resultam na evolução de um ente. Neste caso, a IES e a transição do modelo tradicional para o emergente.

Esta similitude, organismos com IES, advém, também, do fato descrito acima por Debald e Golfeto (2016), que aborda o movimento de evasão e consolidação do contingente, tanto de indivíduos do corpo discente como do docente. Este processo parece muito com a seleção natural, típica do darwinismo.

Figura 3. Esquema do sistema de implantação de um modelo emergente de educação em uma IES.

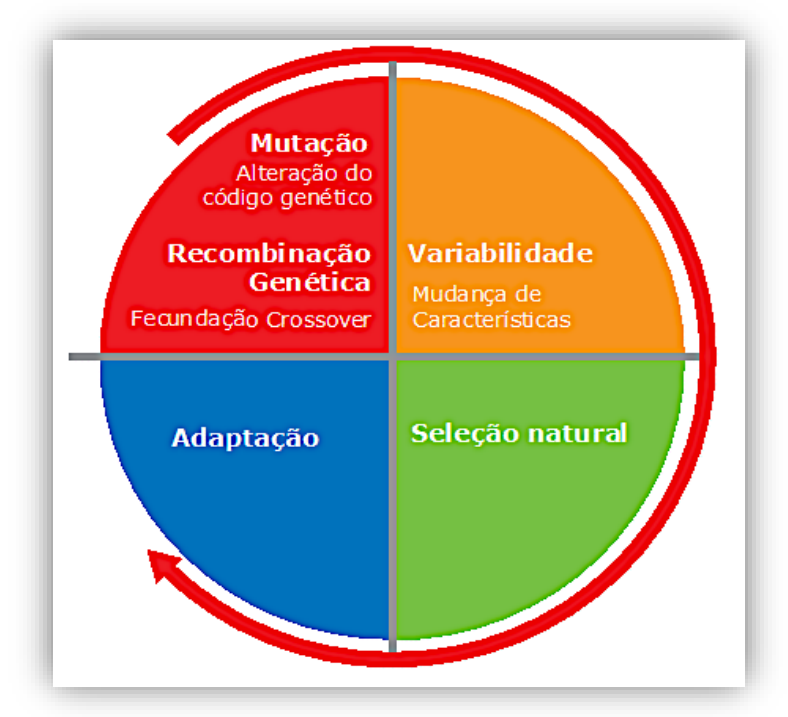

Fonte: Autores (2020)

Assim, o processo cíclico do modelo de implantação tem prazo indefinido, porém passa pela fase de mutação (do modelo tradicional para o emergente) e recombinação genética (cruzamento de elementos do modelo tradicional com o emergente), depois pela variabilidade (as mudanças das características começam a se evidenciar), vai para a seleção natural (evasão e consolidação dos estudantes e professores) chegando a adaptação com a inclinação para o modelo emergente. $\mathrm{O}$ processo se reinicia, ad infinitum, em busca da configuração mais adequada as contingências do ambiente.

\section{Validação}

O esquema apresentado na Figura 02, Instituição de ensino superior como um organismo, foi submetido a validação através de uma pesquisa estruturada aplicada por meio de formulário disponibilizado via internet, na semana de 23/11/2020 a 27/11/2020. Este instrumento de pesquisa solicitava a alguns agentes envolvidos diretamente no processo de implantação do modelo educacional emergente do UniAmérica e do UniSales que identificassem os principais elementos que fizeram parte do processo de implantação do novo sistema educacional adotado nas IES.

A pesquisa se estruturou sobre a ideia da IES em três dimensões: (1) Sistema de

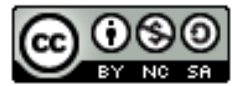



of Production Engineering, 7(4), Edição Especial "Educação 5.0: Inovação e metodologias ativas para o ensino superior, 1-10.

Aprendizagem; (2) Administração e (3) Infraestrutura. Onde, cada uma das três dimensões (1, 2 e 3) seria vista por três prismas: (A) Agentes; (B) Recursos materiais e (C) Processos que é a que consta na Figura 02. Houve total aceitação do esquema estrutural, pois as repostas fluíram plenamente com apresentação de uma variada gama de elementos em cada uma das três dimensões e seus respectivos prismas. "Em nossa perspectiva, a confluência e sinergia destas três dimensões dentro de uma instituição de ensino, é ponto crítico de sucesso para implentação de qualquer projeto/processo de mudança. ” Diz Gilberto Zembrani Júnior, Próreitor de Gestão Acadêmica do UniAmérica ${ }^{1}$, um dos respondentes da pesquisa supracitada.

Com as respostas que validaram o esquema estrutural decorreu uma análise de conteúdo. Foi como que sobre o esqueleto (esquema estrutural) se dispusesse a musculatura do ser, isto é, a expressão da experiência dos agentes envolvidos diretamente no processo de implantação do modelo educacional emergente consolidou de forma concreta e evidente confirmando, assim, o esquema da implantação.

\section{Mapeamento da implantação do modelo emergente de educação}

Com base no esquema da Figura 2, Instituição de ensino superior como um organismo, relacionado aos elementos expressos nas respostas da pesquisa aplicada aos agentes envolvidos, pode-se arriscar um mapeamento generalista dos elementos que são necessários para a implantação do modelo emergente de educação.

Para tanto, deve-se ter em mente que conceitos aqui empregados são somente operacionais, servem para construí a lógica utilizada, logo eles não têm a pretensão de serem unívocos ou mesmo absolutos.

1 - Sistema de Aprendizagem - Que pode ser significado como a "[...] associação combinatória de elementos diferentes." (Morin, 2005 p.19) utilizada para produzir a aprendizagem. No caso, a aprendizagem entendida, de acordo com a visão de Carl Roger, como processo humanístico que considera: "[...] aluno como pessoa e [...]" que "[...] o ensino deve facilitar a sua auto realização, visando à aprendizagem "pela pessoa inteira", que transcende e engloba as aprendizagens afetiva, cognitiva e psicomotora." (Osteman e Cavalcanti, 2010)

2 - Administração - No "[...] sentido de "gerir uma atividade", essa palavra se soma ao prefixo AD-, "junto". Logo, "administrar" dá a noção de "servir ou auxiliar junto a" (uma instituição ou organização, por exemplo)." (Origem das Palavras, 2004-2020), assim, administração seria a gestão de agentes para se chegar a um determinado fim institucionalizado.

3 - Infraestrutura - Todo o recurso físico e material, espaços, instalações e equipamento necessários e indispensáveis para a operacionalização do sistema de aprendizagem e da administração de uma instituição.

A - Agentes - Seriam os setores ou as categorias de profissionais que podem ser mobilizadas para implementar o novo sistema de aprendizagem.

B - Recursos materiais - Tudo o que for necessário utilizar para fazer o processo de transição do modelo anterior de educação para o atual.

C - Processos - Quaisquer ações continuadas, ou realizações contínuas e prolongadas de

${ }^{1}$ Trecho extraído da resposta de Gilberto Zembrani Júnior que consta no formulário aplicado via internet (23 a 27/11/2020) como instrumento de pesquisa deste artigo. 
algumas atividades que são necessárias para implementar o novo sistema de aprendizagem.

Desta forma, considerando a instituição de ensino superior em três dimensões: (1) Sistema de Aprendizagem; (2) Administração e (3) Infraestrutura e que, em cada uma destas três dimensões, pode-se lidar com a realidade a partir de três prismas: (A) Agentes; (B) Recursos materiais e (C) Processos, deve-se levar em conta os seguintes pontos para implantar o modelo emergente de educação.

Quadro 01. Sistema de Aprendizagem

\begin{tabular}{|c|c|c|}
\hline A-Agentes & B - Recursos materiais & C-Processos \\
\hline $\begin{array}{c}\text { - Coordenadores de } \\
\text { cursos; } \\
\text { - Diretorias e Gestores; } \\
\text { - Equipe administrativa; } \\
\text { - Equipe da coordenação } \\
\text { de cursos; } \\
\text { - Equipe da coordenação } \\
\text { pedagógica; } \\
\text { - Equipe da diretoria } \\
\text { acadêmica; } \\
\text { - Equipe de apoio } \\
\text { acadêmico; } \\
\text { - Equipe de apoio do } \\
\text { campus; } \\
\text { - Equipe de EAD; } \\
\text { - Equipe de marketing; } \\
\text { - Equipe de suporte ao } \\
\text { docente; } \\
\text { - Equipe de suporte ao } \\
\text { estudante; } \\
\text { - Equipe de tecnologia da } \\
\text { informação; } \\
\text { - Professores/Consultores } \\
\text { convidados; } \\
\text { - Professores/docentes. }\end{array}$ & $\begin{array}{l}\text { - Ambiente de aprendizagem/Sala de aula } \\
\text { adequados com lay out otimizado e flexível, } \\
\text { mobiliário ergonômico, conforto térmico, } \\
\text { lumínico e acústico e com recursos } \\
\text { audiovisuais pertinentes e tecnologia da } \\
\text { informação apropriada disponibilizada; } \\
\text { - Ambiente para atendimento aos estudantes; } \\
\text { - Ambientes administrativos para } \\
\text { coordenadores de curso; } \\
\text { - Ambientes administrativos para professores; } \\
\text { • Biblioteca digital; } \\
\text { • Laboratórios para aulas práticas; } \\
\text { - Notebooks disponibilizado para uso pelos } \\
\text { estudantes; } \\
\text { - Plataformas de interface compatível com os } \\
\text { estudantes; } \\
\text { - Sistema de acesso à internet facilitado; } \\
\text { - Tecnologia da informação adequada } \\
\text { acessível no campus. }\end{array}$ & $\begin{array}{c}\text { • Capacitação continuada para } \\
\text { apropriação e adoção de novos } \\
\text { procedimentos para o/os: } \\
\text { - Corpo docente, } \\
\text { - Corpo de coordenadores, } \\
\text { - Agentes em geral; } \\
\text { - Apropriação e adoção das metodologias } \\
\text { de: } \\
\text { - Aprendizagem ativa, incluindo o PBL, } \\
\text { - Aprendizagem just-in-time, } \\
\text { - Desafios e projetos, } \\
\text { - Desenvolvimento e avaliação por } \\
\text { competências, } \\
\text { - Projeto integrador de extensão, } \\
\text { - Trabalhos em grupo; } \\
\text { - Apropriação e adoção do uso da/do: } \\
\text { - Avaliação do processo, } \\
\text { - Estratégias de aprendizagem, } \\
\text { - Planejamento de atividades de } \\
\text { aprendizagem; } \\
\text { - Apropriação e adoção da postura do } \\
\text { professor como mediador/preceptor; } \\
\text { • Apropriação e adoção da visão } \\
\text { empreendedora no ambiente } \\
\text { acadêmico; } \\
\text { - Aceitação do protagonismo estudantil; } \\
\text { - Capacitação continuada sobre como } \\
\text { elaborar questões e itens para } \\
\text { avaliações/provas. }\end{array}$ \\
\hline
\end{tabular}

Fonte: Autores (2020)

Quadro 02. Administração

\begin{tabular}{|c|c|c|}
\hline A - Agentes & B - Recursos materiais & C - Processos \\
\hline $\begin{array}{l}\text { - Atendentes ao público em } \\
\text { geral; } \\
\text { - Atendentes da recepção } \\
\text { das secretarias; } \\
\text { - Atendentes do setor } \\
\text { comercial; } \\
\text { - Atendentes do setor } \\
\text { financeiro; } \\
\text { - Atendentes dos } \\
\text { estudantes na recepção; } \\
\text { - Equipe de gestão com } \\
\text { pessoas; } \\
\text { - Equipe da portaria; } \\
\text { - Equipe da secretaria } \\
\text { acadêmica; } \\
\text { - Equipe da tutoria; } \\
\text { - Equipe da zeladoria; } \\
\text { - Equipe de manutenção; } \\
\text { - Equipe do call center; }\end{array}$ & $\begin{array}{l}\text { - Adoção de uma identidade visual alinhada o } \\
\text { conceito de renovação e inovação a qual a } \\
\text { IES se propõe, assim como, a aplicação } \\
\text { planejada de seus elementos gráficos } \\
\text { considerando todos os ambientes que } \\
\text { integram a administração; } \\
\text { - Ambiente administrativos adequados com } \\
\text { lay out otimizado, mobiliário ergonômico, } \\
\text { conforto térmico, lumínico e acústico e } \\
\text { configurados de tal forma que transmitam o } \\
\text { conceito de renovação e inovação a qual a } \\
\text { IES se propõe; } \\
\text { - Remodelação dos ambientes como a/o: } \\
\text { - Biblioteca adaptando com novas cabines } \\
\text { de estudos individuais e em grupos, } \\
\text { - Salas de aula com mudança do mobiliário, } \\
\text { especialmente as mesas, cadeiras e } \\
\text { utilização de pufes e, também, a aplicação } \\
\text { de cores mais vivas de uma forma geral, }\end{array}$ & $\begin{array}{c}\text { - Apropriação e adoção da contratação de } \\
\text { técnico-administrativos, professores e } \\
\text { coordenadores baseado em } \\
\text { competências e no alinhamento com os } \\
\text { valores da cultura e com a missão da } \\
\text { instituição; } \\
\text { - Contratação de novos colaboradores } \\
\text { para integrar o corpo funcional em } \\
\text { especial para compor a equipe do setor } \\
\text { tecnologias e gestão educacional; } \\
\text { • Readequação das funções } \\
\text { administrativas com a alocação de } \\
\text { colaboradores em espaços novos como: } \\
\text { - Atendimento aos estudantes } \\
\text { - Apoio ao docente } \\
\text { - Apoio tecnológico } \\
\text { - Setor comercial } \\
\text { - Setor de marketing } \\
\text { - Apropriação e adoção do modelo de }\end{array}$ \\
\hline
\end{tabular}



of Production Engineering, 7(4), Edição Especial "Educação 5.0: Inovação e metodologias ativas para o ensino superior, 1-10.

- Equipe do setor comercial;

- Equipe de marketing;

- Equipe do setor de relacionamento.
- Atendimento aos estudantes, - Espaços de convivência e alimentação,

- Recepção com o emprego de cores mais vivas;

- Criação de laboratórios anexos a sala (quando não requer cuidados específicos);

- Organização de novos espaços para os coordenadores de curso;

- Ampliação dos links exclusivos da internet atendimento centrado no usuário, visando os aluno e/ou público externo;

- Treinamento continuo a todos os agentes ligados a administração da instituição.

Fonte: Autores (2020)

Quadro 03. Infraestrutura

\begin{tabular}{|c|c|c|}
\hline A - Agentes & B - Recursos materiais & C - Processos \\
\hline $\begin{array}{l}\text { - Equipe da zeladoria; } \\
\text { - Equipe de apoio de sala } \\
\text { de aula; } \\
\text { - Equipe de manutenção, } \\
\text { conservação de espaços e } \\
\text { de mobiliários; } \\
\text { - Equipe de tecnologia da } \\
\text { informação e gestão } \\
\text { educacional; } \\
\text { - Técnicos de Informática. }\end{array}$ & $\begin{array}{l}\text { - Aquisição de equipamentos de TIC para as } \\
\text { salas de aula; } \\
\text { - Aquisição de notebooks para empréstimo ao } \\
\text { corpo discente; } \\
\text { - Aquisição de notebooks, computadores e } \\
\text { outros equipamentos de tecnologia para uso } \\
\text { específico nas atividades administrativas; } \\
\text { - Aumento da velocidade do link de internet; } \\
\text { - Configuração de vários roteadores de alta } \\
\text { capacidade pelo campus. }\end{array}$ & $\begin{array}{l}\text { - Adoção da plataforma Blackboard } \\
\text { como ambiente AVA; } \\
\text { - Atendimento e suporte as demandas } \\
\text { durante as aulas de forma ágil; } \\
\text { - Aumento da capacidade de internet; } \\
\text { - Disponibilidade de rede wi-fi em toda } \\
\text { IES; } \\
\text { - Empréstimo de equipamentos aos } \\
\text { alunos de forma ágil e fácil; } \\
\text { - Informatização dos processos } \\
\text { acadêmicos e das ações da secretaria } \\
\text { acadêmica, da biblioteca e demais } \\
\text { setores administrativos; } \\
\text { - Wi-fi livre sem necessidade de login ou } \\
\text { qualquer tipo de autenticação. }\end{array}$ \\
\hline
\end{tabular}

Fonte: Autores (2020)

Os quadros 1, 2 e 3 trazem um rol de elementos que são dinâmicos. Alguns deles podem ser suprimidos e outros acrescidos diante do contexto em que estiverem inseridos. No entanto, estes quadros (1, 2 e 3 ) possibilitam uma base gerativa para a produção de novas análises de ambientes visando um planejamento da implantação de um modelo emergente de educação em outras IES.

Estes elementos, que estão exposto nos quadros 1, 2 e 3, por sua vez, podem ser manipulados a partir do sistema de implantação de um modelo emergente de educação em uma IES (Figura 3) dando a condição da visualização de um esquema abstrato e controlável do processo de implantação do paradigma emergente em uma IES que está submetida a esta adaptação.

Assim cria-se ideação esquemática para ter um panorama geral ou específico em qualquer uma das fases que esteja. Pode ser utilizado na demonstração conceitual na introdução do modelo, para iniciar um processo de Implantação, verificar e conduzir processos durante a maturação e, também, para materializar a representação da consolidação do paradigma emergente educacional em uma IES.

\section{Considerações Finais}

O que se pretendia investigar era se seria possível elaborar o mapeamento do processo de implantação da metodologia de ensino-aprendizado do paradigma emergente por meio da sistematização do processo de inserção do atual modelo educacional adotado pelo Centro Universitário Salesiano (UniSales) e, também, pelo Centro Universitário União das Américas (UniAmérica), diante destas algumas inferências se pode apresentar.

Por meio da pesquisa exploratória e descritiva, utilizando como instrumento a entrevista

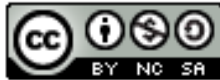


estruturada a partir de um esquema hipotético, e a elaboração da análise de conteúdo pôde-se inferir, pela metodologia racional, um esquema da Instituição de ensino superior como um organismo composto em três dimensões: (1) Sistema de Aprendizagem; (2) Administração e (3) Infraestrutura. Onde, cada uma das três dimensões (1, 2 e 3) seria vista por três prismas: (A) Agentes; (B) Recursos materiais e (C) Processos apresentado na Figura 2.

Este esquema fornece elementos (exposto nos quadros 1, 2 e 3) como matéria prima para a produção daquilo que na prática efetivará a realização do sistema educacional adotado pela IES, apresentado no outro esquema que consta na Figura 3. Este segundo esquema trata do processo de adaptação do modelo tradicional para o paradigma emergente da educação que passa por algumas fases (mutação e recombinação genética, variabilidade, seleção natural e adaptação) e é cíclico de acordo com a dinâmica ambiental em que a IES está inserida.

Desta forma, o mapeamento da implantação do modelo emergente de educação se concretiza, pois seu esquema é um fato (Figuras 3 e 4 e Quadros 1. 2 e 3) e sua essência está enunciada neste artigo.

Além disto há outro ponto notável a se considerar: o esquema para uma implantação comore esta que foi esquematizada neste artigo, não pode ser unidimensional, isto é, focado somente no sistema de aprendizagem. $\mathrm{O}$ esquema deve, necessariamente, incluir sempre as dimensões administrativa e de infraestrutura

A implementação de um novo modelo educacional que propõe um sistema de aprendizagem inovador promove e necessita de reformulação na infraestrutura e na gestão da IES. Todos os procedimentos de gestão, assim como a infraestrutura devem ser pensados para atender ao novo modelo educacional em implantação. É fundamental que isso ocorra para efetivamente estruturar a nova cultura implícita no modelo definido. (Norma Viapiana, Vice-reitora do UniAmérica²).

Aqui foram lançadas as bases conceituais do referido mapeamento, no entanto, esta ontologia carece de uma empiria, este fato cria uma excelente oportunidade para desdobramentos de uma temática para outras pesquisas acadêmicas neste universo.

\section{Referências}

Debald, B. S., \& Golfeto, N. V. (2016). Protagonismo Estudantil e Metodologias Ativas de Aprendizagem em Tempos de Transformação na Educação Superior. Pleiade, 10(20): 05-11

Gerhardt, T. E., \& Silveira, D. T. (2009). (org). Métodos de pesquisa. Porto Alegre: Editora da UFRGS.

Gil, A. C. (2002). Como elaborar projetos de pesquisa. 4. ed. São Paulo: Atlas, Origem das Palavras. Recuperado de https://origemdapalavra.com.br/pergunta/pergunta-199/

Ostermann, F., \& Cavalcanti, C. J. de H. (2010). Teorias de Aprendizagem: Texto introdutório. POA: UFRS-Instituto de Física, 2010. Recuperado de http://files.pibid-unibrsao-vicente.webnode.com/200000051-0d0a70e086/Teorias\%20de\%20aprendizagem.pdf

Rampazzo, L. (2005). Metodologia Científica. Para alunos dos cursos de graduação e pósgraduação. São Paulo: Edições Loyola.

Morin, E. (2015). Introdução ao Pensamento Complexo. $5^{\mathrm{a}}$ Ed. POA: Sulina.

\footnotetext{
${ }^{2}$ Trecho extraído da resposta de Norma Viapiana que consta no formulário aplicado via internet (23 a 27/11/2020) como instrumento de pesquisa deste artigo
} 